\title{
Impacts of Prosopis juliflora L. on Soil Seed Bank Flora in Amibara Rangeland of Afar Regional State, Ethiopia
}

Ali Noha, Lisanework Nigatu, Rejila Manikandan

10.18805/ag.D-347

\begin{abstract}
Background: Prosopis juliflora L. is an evergreen exotic weedy species seriously devastating valuable rangeland resources in arid and semi-arid parts of Ethiopia. Its increasing alarming rate of invasiveness had affecting the livelihood of the pastoral communities in Amibara rangeland of Afar National Regional State. Therefore, the aim of this study was to investigate the effects of Prosopis juliflora L. on soil seed bank flora.

Methods: The total of 20 soil samples were collected from five sites by measuring sample quadrats of $(20 \mathrm{~m} \times 20 \mathrm{~m})$ area were laid out and the soil samples from each quadrant were taken from 5 sub-quadrats $/ \mathrm{m}^{2}$, one from the center and four from the corners, at two depths $(0-3 \mathrm{~cm}$ and $3-10 \mathrm{~cm})$. The soil samples from the identical layers were mixed in plastic bags to form composite sample. Finally, the composite samples were transported to the Haramaya University to conduct seed germination test in the greenhouse. The soil samples were spread thinly $(2 \mathrm{~cm}$ thickness) over sterilized soil in shallow trays $(20 \mathrm{~cm} \times 25 \mathrm{~cm})$ placed on a bench and allowed for seed germination.

Result: The total of 38 herbaceous plant species $/ \mathrm{m}^{2}$ belongs to 16 families were emerged in the upper and lower layer $(0-3 \mathrm{~cm}$ and 3-10 cm) of the soil seed bank samples. The highest values of species diversity were (3.17) in Awash-arba, (3.15) in Alaydagi, (3.04) in Kurkura within $\mathrm{m}^{2}$ area at the depth of $0-3 \mathrm{~cm}$. While the least diversity values of 2.75 in Melka-Werer and 2.77 was recorded in Sarkamo. Jaccard's coefficient similarity index was exhibited high species similarity of $55.6 \%$ in the upper soil seed bank layers $(0-3 \mathrm{~cm})$ in Melka-were and Sarkamo. Whereas, species similarities of $45.2 \%$ were obtained in the lower layer $(3-10 \mathrm{~cm})$ soil seed banks in Awash-arba and upper layer soil seed bank in Alaydagi respectively. While species similarity was decreases as $31.8 \%$ in the lower layer soil seed banks in Sarkamo and Kurkura. Increasing species richness and the diversity was also noticed in under open canopy upper layer soil seed bank samples, while decreasing richness and diversity observed in under closed canopy. This indicates that the Prosopis juliflora L. tree has high growth retarding potential on its under canopy soil seed bank flora and in the lower layer soil seed bank samples also.
\end{abstract}

Key words: Prosopis juliflora L., Seed bank, Species diversity, Species similarity.

\section{INTRODUCTION}

In the past decades, there is a remarkable decrease in pasture lands are threatened the livelihood of the Afar pastoralists in Ethiopia. Moreover, the Afar pastoralists of Northeast Ethiopia have been faced with accelerated social and ecological change which was linked to processes of massive impoverishment and increasing vulnerability. Especially the loss of extensive grazing areas and nomadic mobility resulted in chronic food insecurity. To overcome this problem, the attempts have been made by the government to regulate soil erosion problems in the floodplains of the Awash River. One of these attempts is introduction of fast growing species such as Prosopis juliflora to restore degraded lands and protect against soil erosion. Prosopis juliflora was introduced to the arid and semi-arid regions of Ethiopia in late 1970s and early1980s mainly for the purpose of soil and water conservation (Tegegn, 2008).

In Ethiopia, Prosopis juliflora invasion has been devastating rangeland areas have been degraded and forage grass productivity has declined drastically as (Wakie et al., 2012). Although Prosopis juliflora was introduced on purpose for regulating wind speed and for regulating water induced soil erosion, it has developed unforeseen negative
School of Natural Resources Management and Environmental Sciences, College of Agriculture and Environmental Science, Haramaya University, Haramaya, Dire Dawa, Ethiopia.

Corresponding Author: Rejila Manikandan, School of Natural Resources Management and Environmental Sciences, College of Agriculture and Environmental Science, Haramaya University, Haramaya, Dire Dawa, Ethiopia. Email: rejularaja@gmail.com

How to cite this article: Noha, A., Nigatu, L. and Manikandan, R. (2021). Impacts of Prosopis juliflora L. on Soil Seed Bank Flora in Amibara Rangeland of Afar Regional State, Ethiopia. Agricultural Science Digest. 41(4): 566-571. DOI: 10.18805/ag.D-347.

Submitted: 17-03-2021 Accepted: 18-08-2021 Online: 09-09-2021

outcomes leading to loss of enormous ecosystem services (Ayanu et al., 2015). However, spreading of this invasive alien plant species has become a major problem threatening the livelihoods of people in the Awash Basin, particularly the middle and lower Awash Region such as Baadu, Amibara and Dubti. After being well-established in the introduction sites, the species turned to be invasive and spread to larger areas and it is continuously spreading at an alarming (Yohannes, 2014). 
Impacts of Prosopis juliflora L. on Soil Seed Bank Flora in Amibara Rangeland of Afar Regional State, Ethiopia

Weeds are the most serious but less noticeable yielddeteriorating factor that also poses allelopathic effects against crops and weed species (Khan et al., 2004; Akter and Islam, 2019) due to presence of organic compounds, which release phytotoxic substance. The phytotoxic substances release chemicals into the ecosystem in the form of secondary metabolites which may leach out from various parts of plants to the surrounding rhizosphere either as exudates or rain-residues which impact on germination and growth processes of other plants (Ashok et al., 2005).

The leaves of Prosopis juliflora contain various allelochemicals including tannins, flavonoids, steroids, hydrocarbons, waxes and alkaloids (Pasiecznik et al., 2001). These are assumed to have effects on the germination and growth of other plant species. As a result of this, the plant diversity) will be affected by the Allelochemicals. However, diffused light under Prosopis juliflora canopy also make other plant species survival difficult. It is imperative that evaluation of the Allelopathic potentials of Prosopis juliflora is paramount significance for the assessment of the ecological and environmental implications of this invasive alien species on indigenous plant species biodiversity. Moreover, the information is useful for species selection and management of introduced plant species, especially if the aim of exotic species introduction is to implement an integrated land use. However little/ or scanty investigation are documented with regards to effects of Prosopis juliflora on local biodiversity in Amibara, Afar regional State. Therefore, the aim of this study was to investigate the effects of Prosopis juliflora on soil seed bank flora in the selected site of Amibara district, Afar Regional State, Ethiopia.

\section{MATERIALS AND METHODS Description of the study area}

The study area is located at the Southern parts of Afar National Regional State, Ethiopia in particularly, Amibara administrative district of Gabi-rasu (zone 3) (Fig 1). From this district five localities were randomly selected (MelkaWerer, Sarkamo, Awash-Arba, Alaydagi and Kurkura). It is located $09^{\circ} 28^{\prime} 09.4^{\prime \prime} \mathrm{N}-09^{\circ} 17^{\prime} 18.8^{\prime \prime} \mathrm{N}$ and $40^{\circ} 18^{\prime} 53.8^{\prime \prime} \mathrm{E}-$ $40^{\circ} 10^{\prime} 08.1^{\prime \prime} \mathrm{E}$, about $285 \mathrm{~km}$ north-east of Addis Ababa at an altitude of $740 \mathrm{~m}$ (WARC and APARI, 2007). Amibara district covers the flood fed pastures and temporary wetlands. The district share boundaries with Dulecha and Awash Fentale districts in the West and South West; Awash Fentale district and Oromia Region in the South and South East; Somali and Oromia Region in the East and Gewane district in the North. From the total area of the Gabi-Rasu Zone, Amibara District covers about $17 \%$ of the land area (Shetie, 2008).

\section{Climate}

The study area is characterized by high moisture deficit because of high evapo-transpiration. Mean annual evapotranspiration is $2702 \mathrm{~mm}$ which much exceeds mean annual rainfall of the area which is about $562 \mathrm{~mm}$. The mean maximum temperature is $34.1^{\circ} \mathrm{C}$ and the minimum mean temperature is $19^{\circ} \mathrm{C}$. The maximum and the minimum temperatures are $38^{\circ} \mathrm{C}$ and $14.2^{\circ} \mathrm{C}$ in June and November respectively (WARC and APARI, 2007).

\section{Land use land cover}

Amibara District can be generally classified into state farm, open bush land, bush land, shrub land, open grassland, seasonal marshland and bare land. The distribution of land use/land cover unites of the study area are categorized into seven classes (Abdurahman, 2002). These are Prosopis juliflora cover, grazing lands, Acacia woodlands, shrub lands, settlements, forests and agricultural lands (Shetie, 2008).

\section{Livelihoods}

The livelihood of pastoral community in the study area is mainly depends on livestock production. However shifting their Rangelands into Prosopis encroachment leads to lose the most important forage resources and massive lose in viability of livestock production. As the result the livelihood of pastoral community deliberately disturbed in the study area.

\section{Sampling techniques, sample collection and preparation}

Gabi-Rasu (zone three) is one of five administrative zones of Afar National Regional State and consists of six Administrative districts including Arguba special district
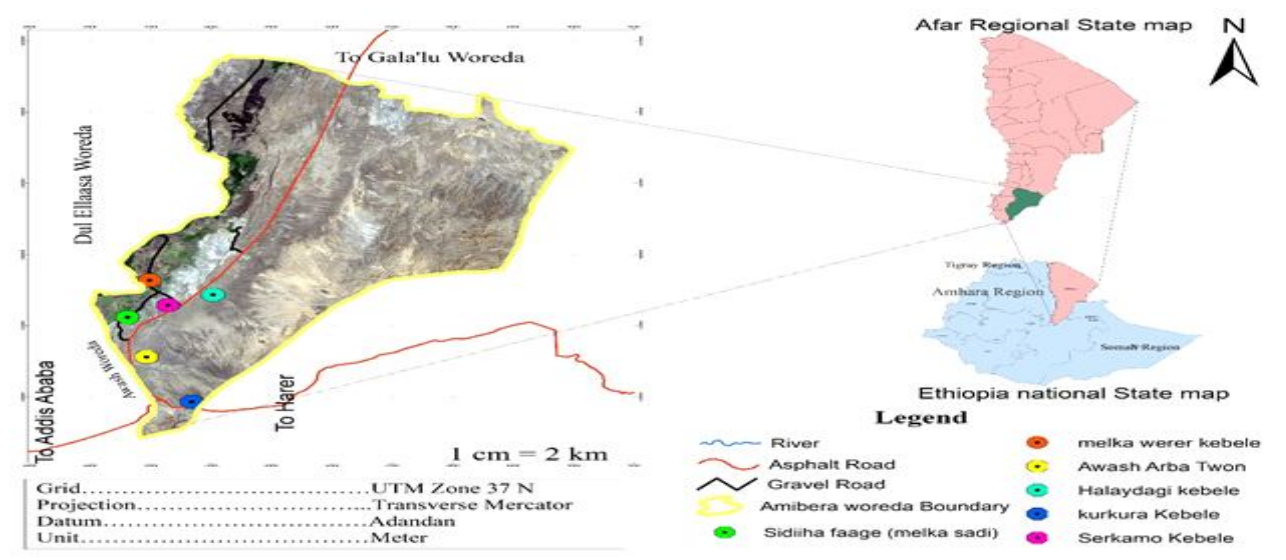

Fig 1: Map of study site location Amibara district. 
(namely Amibara, Awash Fentale, Galalu, Dulecha and Gewane). Among those districts Amibara was purposely selected, due to accessibility of road, degradation of rangeland resources and high infestation of $P$. juliflora and severity of the $P$. juliflora impacts on the livelihoods of the community. Accordingly the five localities (kebeles) such as Melka-Werer, Sarkamo, Awash-Arba, Alaydagi and Kurkura were selected to represent the district. A total of twenty sample plots were selected (four plots from each localities).

\section{Determination of soil seed bank}

The sample quadrats measuring $20 \mathrm{~m} \times 20 \mathrm{~m}$ area were laid out and the soil samples from each quadrat were taken from 5 sub-quadrats $/ \mathrm{m}^{2}$, one from the center and four from the corners, at two depths $(0-3 \mathrm{~cm}$ and $3-10 \mathrm{~cm})$ to explore a possible variation in the depth of the distribution of the seeds within the same sample quadrats of the soil. The soil samples from the identical layers were mixed in plastic bags to form composite sample (Tessema et al., 2017). Finally, the composite samples were transported to the Haramaya University, Haramaya, Ethiopia to conduct germination test in the greenhouse.

In the greenhouse, the collected soil samples were spread thinly ( $2 \mathrm{~cm}$ thickness) over sterilized soil in shallow trays $(20 \mathrm{~cm} \times 25 \mathrm{~cm})$ placed on a bench. Two control trays spread only with sterilized soil was also placed along the experimental trays to monitor for greenhouse contamination. Water was applied to each tray to keep it moist. The emerged and readily identifiable seedlings were counted, recorded and discarded every week. The species which was difficult to identify at the seedling stages was counted, labeled, transplanted and was grown separately till it was certainly identified. Each month, the soil samples were stirred to stimulate more seed germination. The experiment was continued for about six months to allow species with long term dormancy to germinate. The emergence values from each tray was converted to those possible from an area of one $\mathrm{m}^{2}$ the soil seed bank.

\section{Data analysis}

The diversity of the species in the soil seed bank under the canopy of Prosopis juliflora in the rangeland of Amibara was compared using Shannon diversity index (Shannon and Weaver, 1963). The species index was used to assess the impact of Prosopis juliflora on herbaceous plant species diversity. The higher value of the index of the diversity indicates variability in the type of species and heterogeneity in the community where as the lesser values show the existence of homogeneity in the community.

$$
\text { Shannon-Wiener index of diversity: } \mathrm{H}^{\prime}=-\left(\sum_{\mathrm{i}=1}^{\mathrm{s}} P_{\mathrm{i}} \ln P_{\mathrm{i}}\right)
$$

In addition, the evenness of the species was calculated as suggested by Hill (1973):

$$
E=\frac{\exp (H)}{\ln s}
$$

Evenness index indicates as to how equally abundant each species would be in the plant community where high evenness shows that the ecosystem is healthy as there is no species in the ecosystem that dominates other species. Evenness or equitability assumes a value of 0 to 1 , where 1 show for complete evenness and 0 indicates the dominance of a single species in the area.

The similarity of the soil seed bank flora and the aboveground vegetation were compared using Jaccard's coefficient of similarity (JCS) as described by Ludwig and Reynolds (1988).

$$
J C S=\frac{a}{a+b+c}
$$

The coefficient has a value from 0 to 1 , where 1 indicates complete similarity and 0 shows complete dissimilarity. Analysis of variance were undertaken and the means were compared using Duncan's multiple range test at $5 \%$ level of significance when ANOVA showed the occurrence of a significant difference for each of the variables under consideration. The data collected on germination bioassay and greenhouse experiment were subjected to analysis of variance using SAS (version 9) software program. Simple descriptive statistics, one way ANOVA and Duncan's multiple range tests were used for data analysis. All data were tested at $p<0.05$ level in order to investigate if significant differences existed among treatments.

\section{RESULTS AND DISCUSSION \\ Effects of Prosopis juliflora L. on soil seed bank herbaceous plant species diversity}

Species diversity, composition, richness and evenness were studied in the soil seed bank samples that where collected under the canopy of $P$. juliflora. The floral diversity result showed that the total composition of 38 herbaceous species $/ \mathrm{m}^{2}$ were emerged in the upper and lower layer $(0-3 \mathrm{~cm}$ and 3-10 $\mathrm{cm}$ ) of the soil seed bank samples, 27 were forbs (18 annual and 9 perennial), 10 grasses ( 7 perennial and 3 annual) and 1 perennial shrub species. Total of thirty eight herbaceous species belonging to 16 families were identified in the soil seed banks $/ \mathrm{m}^{2}$. From those identified majority belong to family Poaceae (Table 1). The three top frequent families in the study area were Poaceae, Asteraceae and Fabaceae. Most of the recovered species from the soil seed bank were grasses and herbs. In line with this, similarly, De Andrade and Miranda (2014) found that Poaceae (64\%) are often the most abundant species.

This result is in agreement with the studies of Assefa (2011) that reported the emergence of five woody plant species in the seed bank study, Bezawit forest at Abay Millennium Park, Northwest Ethiopia. The low number of seeds in the soil seed bank for most species could also be the result of short residence time of most woody species Teketay (2005). Senbeta et al. (2002) reported that, most of the woody species in the dry afromontane forests of Ethiopia depend on seed rain and formation of seedling banks under the shades of mature forest canopy as strategies for regeneration. 
Impacts of Prosopis juliflora L. on Soil Seed Bank Flora in Amibara Rangeland of Afar Regional State, Ethiopia

Table 1: List of plant species recorded in soil seed banks in study area.

\begin{tabular}{llll}
\hline Scientific name & Family name & Scientific name & Family name \\
\hline Prosopis juliflora & Fabaceae & Enteropogon rupestris & Poaceae \\
Acalypha indica & Euphorbiaceae & Euphorbia geniculata & Euphorbiaceae \\
Achyranthes aspera & Amaranthaceae & Euphorbia prostrata & Euphorbiaceae \\
Aerva javanica & Amaranthaceae & Heliotropiuim cinerascens & Boraginaceae \\
Aeschynomene abyssinica & Fabaceae & Hibiscus spp & Malvaceae \\
Alternathera repens & Amaranthaceae & Indigofera caerulea & Fabaceae \\
Amaranthus dubius & Amaranthaceae & Justicia flava & Acanthaceae \\
Aristida adscensionis & Poaceae & Leucas urticifolia & Lamiaceae \\
Astystasia schimperi & Acanthaceae & Ocimum basilicum & Lamiaceae \\
Baleria acanthiodes & Acanthaceae & Orthosiphon pallidus & Lamiaceae \\
Bothriochloa radicans & Poaceae & Parthenium hystrophorus & Asteraceae \\
Chloris gayana & Poaceae & Portulaca oleracea & Portulacaceae \\
Corchorus trilocularis & Tiliaceae & Rhynchosia tomentosa & Fabaceae \\
Cucumis ficifolius & Cucurbitaceae & Ruellia patula & Acanthaceae \\
Cynodon dactylon & Poaceae & Sporobolus ioclados & Poaceae \\
Cyperus spp & Cyperaceae & Sporobolus pyramidalis & Poaceae \\
Dactyloctenium aegyptium & Poaceae & Tragus berteronianus & Poaceae \\
Datura stramonium & Solanaceae & Tribulus terrestris & Zygophyllaceae \\
Ischaemum afrum & Poaceae & Zaleya pentandra & Aizoaceae \\
\hline
\end{tabular}

\section{Species richness, diversity and evenness}

Species diversity, richness and evenness were determined under different Prosopis canopy soil seed bank within same sample plot at two depth $(0-3 \mathrm{~cm}$ and $3-10 \mathrm{~cm})$ from five sites in Amibara rangeland (Table 2). The highest values of species diversity were (3.17) in Awash-arba, (3.15) Alaydagi and (3.04) inKurkura within $\mathrm{m}^{2}$ area at the depth of $(0-3 \mathrm{~cm})$. While the least diversity values of (2.75) in Melka-Werer and (2.77) was recorded in Sarkamo. Whereas, the high evenness value of (0.96 and 0.95$)$ were registered in Kurkura and Alaydagi. Species richness was simultaneously increased as ascending (24) in Kurkura, (28) in Alaydagi (30) in Awash-arba. But the least values of species richness (21) was recorded in Melka-Wererand Sarkamo (Table 1). Similarly, the highest values of species evenness were observed (0.96) in Kurkura, (0.95) in Alaydagi, (0.93) Awasharba, (0.91) in Sarkamo and the least evenness values of species was recorded in Melka-Werer with the value of $(0.90)$ at depth of $0-3 \mathrm{~cm}$. Therefore, when species richness decreasing, the diversity and evenness was also decreased in the upper layer soil seed banks (Table 2).

Species diversity, richness and evenness were also determined in similar sites with possible variation of depth at $(3-10 \mathrm{~cm})$. The highest value of $(2.69,2.59,2.54$ and 2.54) species diversity were recorded in Awash-arba, Alaydagi, Sarkamo and Kurkura. Whereas, least value of (1.79) species diversity was also recorded in Melka-Werer. High species richness value of (17) in Awash-arba, (16) in Sarkamo, (14) in Alaydagi and (13) in Kurkura. While the least value of (8) species richness was recorded MelkaWerer (Table 2). The evenness values of species was high in Kurkura and Alaydagi with the value (0.99 and 0.98) respectively. Whereas, the remaining three sites such as
Table 2: Effect of Prosopis juliflora on it's under canopy soil seed bank flora.

\begin{tabular}{lcccc}
\hline Site name & Depth & Diversity $(\mathrm{H})$ & Richness & Evenness \\
\hline Free area & Control & 2.73287 & 37 & 0.756835 \\
Awash-Arba & $0-3 \mathrm{~cm}$ & 3.171369 & 30 & 0.9324271 \\
& $3-10 \mathrm{~cm}$ & 2.749246 & 21 & 0.903014 \\
Melka-Werer & $0-3 \mathrm{~cm}$ & 2.775649 & 21 & 0.911686 \\
& $3-10 \mathrm{~cm}$ & 3.040129 & 24 & 0.9566009 \\
Sarkamo & $0-3 \mathrm{~cm}$ & 3.158939 & 28 & 0.9480028 \\
& $3-10 \mathrm{~cm}$ & 2.690829 & 17 & 0.9497444 \\
Kurkura & $0-3 \mathrm{~cm}$ & 1.796494 & 8 & 0.8639311 \\
& $3-10 \mathrm{~cm}$ & 2.545716 & 16 & 0.918173 \\
Alaydagi & $0-3 \mathrm{~cm}$ & 2.540036 & 13 & 0.9902871 \\
& $3-10 \mathrm{~cm}$ & 2.599302 & 14 & 0.9849358 \\
\hline
\end{tabular}

Awash-arba, Sarkamo and Melka-Werer, the evenness of species values were simultaneously decreased as $(0.95$, 0.92 and 0.86 ) in the lower soil seed banks layer (Table 2). Diversity and richness was higher in the upper layer $(0-3 \mathrm{~cm})$ soil seed bank flora $(3.17,3.15,3.04,2.77$ and 2.75$)$ and $(30,28,24$ and 21$)$ than the lower layer $(3-10 \mathrm{~cm})$ with the value of $(2.69,1.79,2.59$ and 2.54) species (Table 2).

The species richness of a site subject to disturbance depends on the differential responses of species; some species may tolerate the disturbances, while others may become locally extinct (Sagar et al., 2003; Mukherjee et al., 2014). We observed much lower species richness than values recorded in previous studies of sites in National Park and Arly National Park, which is also in Burkina Faso (Ouédraogo et al. 2006), possibly because we focused on Prosopis infected area areas where sensitive species may have been eliminated. 
The highest values of species diversity were recorded in upper layer of soil seed bank samples of three localities of the study area. Those localities are: Awash-arba, Alaydagi and Kurkura, with the value of $(3.17,3.15$ and 3.04$)$ respectively. Species diversity was high in under open canopy soil seed bank than under closed canopy soil seed bank. Simultaneously species diversity was declined inunder closed canopy soil seed bank with the value of $(2.75$ and 2.77) in Melka-Werer and Sarkamo. This is due to high accumulation of allelochemicals, low light and humidity within under closed canopy of $P$. juliflora. The invasion of exotic species of $P$. juliflora is the main driving forces to Eradicate predominantly pastoral lands, rangelands that the livelihood of the pastoral community depends on livestock productions. Its toxicity, aggressiveness and fast growing and propagating a vast area with in short time leads to Massive lose in biodiversity and declining livestock productivity as well (Table 2 ).

Similarly species richness and evenness has recorded high value of (30, 28 and 24) in Awash-arba, Alaydagi and Kurkura under open canopy upper layer of soil seed bank samples, while the richness was declined in under closed canopy soil seed bank in Melka-Werer and Sarkamo sites having the same values of (21). The result showed that when increasing species richness and the diversity was also increased in under open canopy upper layer soil seed bank samples, while decreasing richness in under closed canopy the diversity also decreased. This indicates that the tree has high growth retarding potential on it's under canopy soil seed bank flora and in the lower layer soil seed bank samples (Table 2). The mean values of species diversity in terms of Shannon diversity index $\left(H^{\prime}\right)$ and species richness $(R)$ were declining in Prosopis invaded patches than non-invaded area. These were due to the allelopathic and shade effects of the species underneath Prosopis canopy which had reduced seed productivity. Furthermore, greater accumulation of litters underneath the Prosopis canopy could explain the greater inhibition of understory vegetation to produce seeds (Muturi et al., 2013). Under high infestation of Prosopis, we recorded less species richness in SSB when we compare with llukor et al. (2016).

As comparing with the controls species richness was slightly reduced in all soil seed bank sampling areas of Amibara rangeland. There was high variation of effects among soil seed bank sampling site and between soil seed bank depths. In the upper layer $(0-3 \mathrm{~cm})$ soil seed bank samples in under open canopies of $P$. juliflora, species richness, diversity and evenness was affected when compared to not invaded area. In the lower layer of soil seed bank, species diversity, richness and evenness were highly inhibited as the result of high accumulation of poisonous allelochemical compound from different parts of $P$. julflora's litter that percolate into the lower layers of under canopy soil seed bank. This can have more opportunity to delay early growth of species in its understory. Accordingly species richness, diversity and evenness has declined (Table 1). The declining of the species richness, diversity and evenness may be due the presence of exotic species in soil banks could potentially become a source of invasion and risk for future regeneration by competing and changing the ecosystem (Matthew et al., 2004).

\section{Jaccard's coefficient of similarity}

Jacquard's coefficient similarity index was displayed high species similarity of $(55.6 \%)$ in the upper soil seed bank layers at $(0-3 \mathrm{~cm})$ in Melka-were and Sarkamo. Whereas, species similarities of $(45.2 \%)$ were obtained in the lower layer soil seed banks in Awash-arba and upper layer soil seed bank in Alaydagi respectively. While species similarity was decreases as (31.8\%) in the lower layer soil seed banks in Sarkamo and kurkura. However, species similarity decreases in the lower soil seed bank than the upper soil seed bank layers of under $P$. julflora's canopy. There might be more allelochemical residues in the lower soil seed bank layers than that of the upper soil seed bank that highly decreases species similarity (Table 3 ).

The total number of germinated species in the soil seed banks was lower (64 species) than the total number of

Table 3: Jaccard's coefficient of similarity between under canopy soil seed banks depth of $P$. juliflora.

\begin{tabular}{|c|c|c|c|c|c|c|c|c|c|c|c|}
\hline & Depth & $0-3 \mathrm{~cm}$ & $0-3 \mathrm{~cm}$ & $0-3 \mathrm{~cm}$ & $0-3 \mathrm{~cm}$ & $0-3 \mathrm{~cm}$ & $3-10 \mathrm{~cm}$ & $3-10 \mathrm{~cm}$ & $3-10 \mathrm{~cm}$ & $3-10 \mathrm{~cm}$ & $3-10 \mathrm{~cm}$ \\
\hline Site name & & AA & MW & SO & $\mathrm{KK}$ & $A D$ & AA & MW & SO & $\mathrm{KK}$ & $A D$ \\
\hline AAD1 & $0-3 \mathrm{~cm}$ & 1 & & & & & & & & & \\
\hline MWD1 & $0-3 \mathrm{~cm}$ & 0.545 & 1 & & & & & & & & \\
\hline SOD1 & $0-3 \mathrm{~cm}$ & 0.457 & 0.556 & 1 & & & & & & & \\
\hline KKD1 & $0-3 \mathrm{~cm}$ & 0.543 & 0.452 & 0.552 & 1 & & & & & & \\
\hline ADD1 & $0-3 \mathrm{~cm}$ & 0.611 & 0.531 & 0.4 & 0.405 & 1 & & & & & \\
\hline AAD2 & $3-10 \mathrm{~cm}$ & 0.567 & 0.357 & 0.31 & 0.367 & 0.452 & 1 & & & & \\
\hline MWD2 & $3-10 \mathrm{~cm}$ & 0.226 & 0.381 & 0.318 & 0.231 & 0.2 & 0.25 & 1 & & & \\
\hline SOD2 & $3-10 \mathrm{~cm}$ & 0.353 & 0.423 & 0.542 & 0.481 & 0.294 & 0.222 & 0.2 & 1 & & \\
\hline KKD2 & $3-10 \mathrm{~cm}$ & 0.344 & 0.417 & 0.259 & 0.37 & 0.281 & 0.25 & 0.313 & 0.318 & 1 & \\
\hline ADD2 & $3-10 \mathrm{~cm}$ & 0.333 & 0.4 & 0.296 & 0.357 & 0.5 & 0.292 & 0.222 & 0.304 & 0.35 & 1 \\
\hline Control & & 0.737 & 0.541 & 0.541 & 0.622 & 0.73 & 0.395 & 0.189 & 0.444 & 0.324 & 0.389 \\
\hline
\end{tabular}

AAD1= Awash-Arba, D1= 0-3 cm soil depth, MW= Melka-Werer, SA= Sarkamo, KK= Kurkura and AD= Alaydagi, D2= 3-10 cm soil depth. 
species recoded in the understory vegetation 87 species. The total number of annual and perennial grass species emerged from the soil seed banks was lower than the total number of grass species recorded in the understory vegetation.

\section{CONCLUSION}

In this study results were revealed that, the species richness and evenness has recorded high value of 30,28 and 24 in Awash-arba, Alaydagi and Kurkura under open canopy upper layer of soil seed bank samples respectively. While the richness was declined in under closed canopy (Prosopis julflora's canopy) soil seed bank in Melka-Werer and Sarkamo sites having the same values of 21 . The result showed that when increasing species richness and the diversity was also increased in under open canopy upper layer soil seed bank samples, while decreasing richness in under closed canopy the diversity also decreased. This indicates that the tree (Prosopis julflora's canopy) has high growth retarding potential on it's under canopy soil seed bank flora and in the lower layer soil seed bank samples.

\section{REFERENCES}

Abdurahman, A. (2002). The Paradox of Share Cropping in the Middle Awash of Ethiopia. Paper submitted to the $12^{\text {th }}$ International Annual Conference on Ethiopian Economy.

Akter, P. and Islam, M. (2019). Allelopathic effects of root exudates of some weeds on germinability and growth of radish (Raphanus sativus L.) and cucumber (Cucumis sativus L.). Indian Journal of Agricultural Research. 53: 33-38.

Ashok, S. Sajjan and Pawar, K.N. (2005). Studies on allelopathic effects of Parthenium hysterophorus on some crop species. Agricultural Science Digest. 25: 166-169.

Assefa, T. (2011). Assessment of soil seed bank composition in Bezawit Abay Millennium Park, Bahir Dar, Ethiopia (Doctoral dissertation, M.Sc. thesis). Bahir Dar University.

Ayanu, Y., Jentsch, A., Müller-Mahn, D., Rettberg, S., Romankiewicz, C. and Koellner, T. (2015). Ecosystem engineer unleashed: Prosopis juliflora threatening ecosystem services? Regional Environmental Change. 15: 155-167.

De Andrade, L.A.Z., Miranda, H.S. (2014). The dynamics of the soil seed bank after a fire event in a woody savanna in central Brazil. Plant Ecology 15: 1199-209.

Hill, M.O. (1973). Diversity and evenness: A unifying notation and its consequences. Ecology. 54: 427-432.

llukor, J., Rettberg, S., Treydte, A. and Birner, R. (2016). To eradicate or not to eradicate? Recommendations on Prosopis juliflora management in Afar, Ethiopia, from an interdisciplinary perspective. Policy and Practice. 6:14 https://doi.org/ 10.1186/s13570-016-0061-1.

Khan, I., Hassan, G., Khan, K M.I. and Khan, I.A. (2004). Efficacy of some new herbicidal molecules on grassy and broadleaf weeds in wheat-II. Pakistan Journal of Weed Science Resource. 10(1-2): 33-38.
Ludwing, J.A. and Reyonlds, J.F. (1988). Statistical Ecology. Wiley inter Science, New York. Manaaki Whenua Landcare Research. 111p.

Matthew, L., Brooks, C.M., d'antonio, D.M., Richardson, J.B., Grace, J.E., Keeley, J.M., David, P. (2004). Effects of invasive alien plants on fire regimes. Bioscience. 54: 677-688.

Mukherjee, A., Malik, U., Chattopadhay, C. and Barik, A. (2014). Allelopathic effects of the weed, Polygonum orientale L. on jute. Indian Journal of Agricultural Research. 48: 278-286.

Muturi, G.M., Poorter, L., Mohren, G.M.J and Kigomo, B.N. (2013). Ecological impact of Prosopis species invasion in Turkwel riverine forest, Kenya. J. Arid Environ. 92: 89-97.

Ouédraogo, O., Thiombiano, A. and Karen, H. (2006). Diversité et dynamique de la vegetation ligneuse juvéniles du parc national d'Arly (Burkina Faso). Candollea. 64: 257-78.

Pasiencznik, N.M., Felker, P., Harris, P.J.C., Harsh, L.N, Cruz, G., Tewari, J.C., Cadorer, K. and Maldonado, LJ. (2001). The Prosopis juliflora, Prosopis pallida Complex: A Monograph. HADRA, Coventry, $172 \mathrm{pp}$.

Sagar, R., Raghubanshi, A.S., Singh, J.S. (2003). Tree species composition, dispersion and diversity along a disturbance gradient in a dry tropical forest region of India. For Ecol. Manag. 154: 61-71.

Senbeta, F., Teketay, D. and Näslund, B.Å. (2002). Native woody species regeneration in exotic tree plantations at MunessaShashemene Forest, Ethiopia. New Forests. 24(2): 131-145.

Shannon, C.E. and Weaver, W.W. (1963). The mathematical theory of communications. University of Illinois Press, Urbana, p 117.

Shetie, G. (2008) .The Ecological Distribution and Socio-Economic impacts of Prosopis juliflora (Sw.) DC. In the Amibara Woreda, Afar National Regional State.

Tegegn, G.G. (2008). Experiences on Prosopis management case of Afar region. FARM-Africa Technical Report, London.

Teketay, D. (2005). Seed and regeneration ecology in dry Afromontane forests of Ethiopia: I. Seed production-population structures. Tropical Ecology. 46(1): 45-49.

Tessema Z.K., Ejigu, B. and Lisanework, N. (2017). Tree species determine soil seed bank composition and its similarity with understory vegetation in a semi-arid African savanna. Ecological Processes. DOI: 10.1186/s13717-017-0075-7.

Wakie, T., Evangelista, P. and Laituri, M. (2012). Utilization assessment of Prosopis juliflora in Afar region, Ethiopia. United States Forest Service, USDA Office of International Programs, United States Agency for International Development Pastoral Livelihoods Initiative II Project (PLI II).

WARC and APARI (2007). Werer Agricultural Research Center and Afar Pastoral and Agro-pastoral Research Institute. Assessment of Soil Status and Topographic Exploration of Western and South-western Districts of Afar Regional state. Proceedings, pp. 9-36.

Yohannes, Z. (2014). Quantitative Assessment of Invasion of Prosopis juliflora in Baadu, Afar Regional State of Ethiopia. In: Managing Prosopis juliflora for Better (Agro) Pastoral Livelihoods in the Horn of Africa. Proceeding of the Regional Conference, May 1- May 2, Addis Ababa, Ethiopia. 